DOI : $10.22199 / \mathrm{S} 07160917.1982 .0001 .00003$

\title{
ENTREVISTA AL DR. ROLANDO CHUAQUI K.
}

En el mes de Abril, visitó la Universidad del Norte el Dr. Rolando Chuaqui Kettlun (Ph. D., Logic and Methodology of Science, University of California, Berkeley), de conocida trayectoria en Chile, actual Director del Instituto de Matemática de la Universidad Católica de Chile y Presidente de la Sociedad Matemática de Chile. Durante su visita dictó la clase inaugural de la Carrera de Licenciatura en Matemática y se reunió con los académicos del Departamento de Matemática y de otros departamentos, conversando sobre programas de estudios de Carreras Universitarias.

Sus amplios conocimientos y su gran experiencia, le permiten visualizar con claridad los antecedentes características y estructura de los programas de formación de matemáticos. 
Es por eso que consideramos interesante entrevistarlo. En forma muy gentil, él accedió a dar respuesta a las siguientes preguntas.

¿Porqué son poco conocidos los trabajos realizado por matemáticos?

En primer lugar, para comprender los avances matemáticos (que son muchos, hay más de 200 revistas, que se publican en el mundo con nuevas investigaciones), es necesario, en la mayoría de los casos, poseer un nivel de conocimiento muy alto. Un ingeniero o un economista, por ejemplo, distan mucho de obtener en el curso normal de sus carreras los conocimientos matemáticos para comprender, sin una preparación especial, lo que se investiga en la actualidad. Para comenzar a hacer investigación en esta ciencia se necesitan unos seis años de estudios universitarios de matemática. Aún para comprender lo que se hace en investigación, es necesario mucho estudio o largas explicaciones.

En segundo lugar, la dificultad de compresión de los resultados de la investigación matemática, se ve aumentada porque los matemáticos los presentan no en el orden de descubrimiento, sino en si orden lógico. Así, se oculta, la mayoría de las veces, el origen y las motivaciones de estos resultados.

Pese a que la dificultad de comprensión de los avances recientes es común a otras ciencias, como por ejemplo la física, en matemáticas existe un problema adicional para compenetrarse de lo nuevo; y así, llegamos a la tercera causa del desconocimiento de los avances matemáticos que ahora paso a explicar. Lo que no se sabe en matemáticas 
tiene un carácter de certeza que no poseen las otras ciencias. Por esto, lo que se aprende a cualquier nivel es definitivamente verdadero y correcto y nuca se obtendrán nuevos conocimientos que harán desechar lo ya aprendido. Así, todo conocimiento matemático tiene un carácter de finalidad que parece no dar lugar a nuevos avances, y esto explica, en parte, la aparente imposibilidad de su progreso para los que no llegan estudiarla en toda su extensión.

E1 avance en matemática no se realiza por revisión de teorías, como en física, donde por ejemplo, la mecánica de Newton fue reemplazada por la de Einstein. Todo avance en matemática tiene un aspecto común: se demuestran nuevas proposiciones llamadas teoremas. Pero se pueden distinguir dos tipos de avances: por extensión y por profundización. E1 progreso por extensión ocurre de dos maneras distintas: o por la creación de nuevas teorías o por la resolución de problemas (esto es demostración e teoremas) en teorías ya desarrolladas.

¿Cuáles son las posibilidades de trabajo que tiene una persona que se dedica a la Matemática?

En primer lugar, puede dedicarse a la investigación y enseñanza universitaria de matemática. Para esto creo que en el momento actual es necesario completar los estudios de doctorado, ya sea en Chile o en el extranjero. Debido al escaso número de investigadores en matemáticas creo que hay amplio campo profesional en esta área.

En segundo lugar, puede dedicarse a la enseñanza ya sea media o en Institutos profesionales. 
Un tercer ámbito de trabajo, lo constituyen las industrias, instituciones financieras y públicas, etc. En Chile, esta es un área en crecimiento que tiene expectativas claras en computación y Estadística. En otros países, también tienen cabida los especialistas en otras áreas de la matemática. Por ejemplo, en los Estados Unidos la segunda demanda de Masters es para los que se han especializado en matemática. En el país, está comenzando a haber desarrollo en este campo.

¿Cuál es el estado actual de la investigación matemática en Chile?

La investigación matemática en Chile es incipiente (se puede decir que sólo comenzó alrededor de 1970), pero ha habido un marcado progreso en los últimos años. Así hay varios grupos de investigación compuestos, en general, por matemáticos jóvenes. Un estudio más detallado aparece en el libro Una visión de la comunidad científica nacional, publicado por CPU y la Academia de Ciencias.

¿Cuáles son los objetivos de un programa de Licenciatura?

Estos programas deben formar matemáticos para las distintas funciones que especifiqué antes. Así, debe ser la primera etapa en la formación de un investigador y preparar algunos para la enseñanza y el ejercicio profesional.

¿Cuáles son las características que debe tener un programa de Licenciatura? 
E1 programa de Licenciatura debe dar una formación básica en las principales ramas de la matemática, ya sea una especialización en un área de aplicación inmediata, o una profundización que le permita al alumno proseguir su formación como investigador. En todo caso, el programa debe estar constituído por un número reducido de cursos gruesos, de tal manera que no se pueda seguir más de cuatro por semestre. Esto es debido en parte a la importancia mayor de la madurez matemática por sobre la extensión de conocimientos.

¿Qué futuro le prevee a los programas de formación de matemáticos?

Es claro de las consideraciones anteriores que existe una demanda importante de matemáticos en la actualidad y una demanda potencial aún mayor.

En primer lugar, las necesidades de la docencia universitaria de matemática son muy grandes y las plazas disponibles deberían ser llenadas en su mayoría por investigadores probados $o$, por 10 menos, potenciales. En segundo lugar, las necesidades del sistema productivo nacional harán seguramente crecer la demanda de matemáticos. Es de hacer notar que ya existe una amplia demanda de estadísticos y especialistas en computación. 